Open Access

\title{
Ghrelin, adipokines, metabolic factors in relation with weight status in school-children and results of a 1-year lifestyle intervention program
}

Christine Rambhojan ${ }^{1}$, Elodie Bouaziz-Amar 2,3,4, Laurent Larifla 1,5, Jacqueline Deloumeaux ${ }^{1}$, Josiane Clepier ${ }^{6}$, Jean Plumasseau', Jean-Marc Lacorte ${ }^{2,3,4}$ and Lydia Foucan ${ }^{1,8^{*}}$

\begin{abstract}
Background: Overweight in Guadeloupe is a public health matter affecting children and adults. In the present study we evaluated the metabolic profile, including serum ghrelin, leptin and adiponectin levels, in normal weight, overweight and obese school children and we analyzed the potential changes in anthropometric and metabolic risk factors after a 1-year lifestyle intervention program.

Methods: Parameters were assessed at baseline and at 1 year. Three groups $(G)$ were defined according the International Obesity Task Force reference values, G1: normal weight / G2: overweight / G3: obese. The lifestyle intervention included dietary counseling, regular physical activity and family support.

Results: A total of 120 children (G1: $n=44, G 2: n=39, G 3: n=37$ ), aged $11-15$ years and $59 \%$ girls were enrolled. Obese children showed significant lower HDL-C, adiponectin and ghrelin concentrations, higher triglycerides, fasting blood glucose, insulin and leptin levels and also higher frequencies of abdominal obesity (G1: $2.3 \%, G 2$ : $28.2 \%, G 3: 73 \%$ ) and insulin resistance (Gl: $39 \%$, G2: $72 \%$, G3: $89 \%$ ) than the other groups. In the overall sample, the linear regressions exploring the associations of ghrelin, adiponectin and leptin with age, gender, BMl z-score, HOMA-IR and tanner stage as independent variables showed strong associations of leptin levels with weight status and insulin resistance at baseline. The models accounted for $58 \%$ of variability in leptin levels compared with 26 and $15 \%$ for adiponectin and ghrelin levels respectively.

In 83 children who completed the program, significant decreases in BMI z-score in overweight and obese children were noted. Leptin levels decreased significantly only in the obese group whereas adiponectin concentrations increased significantly in the three groups,

In obese children, a significant correlation was found between changes in BMI Z-score, and changes in leptin levels $(r=0.39 ; P=0.049)$ but not with changes in adiponectin levels.

Conclusions: Abdominal obesity and insulin resistance were highly prevalent in obese children highlighting their risk of metabolic complications in adulthood. A 1-year long lifestyle intervention was associated with improvement in BMI z-score and metabolic parameters.
\end{abstract}

Keywords: Adolescents, Obesity, Adipokines, Ghrelin, Lifestyle intervention

\footnotetext{
* Correspondence: Ifoucan@yahoo.fr

${ }^{1}$ Equipe de recherche sur le Risque Cardio métabolique, ECM/LAMIA EA4540,

Université des Antilles et de la Guyane, Guadeloupe, France

${ }^{8}$ Département de Santé Publique, CHU, 97159 Pointe-à-Pitre, Guadeloupe,

FWI, France

Full list of author information is available at the end of the article
}

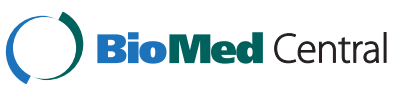

(c) 2015 Rambhojan et al. Open Access This article is distributed under the terms of the Creative Commons Attribution 4.0 International License (http://creativecommons.org/licenses/by/4.0/), which permits unrestricted use, distribution, and reproduction in any medium, provided you give appropriate credit to the original author(s) and the source, provide a link to the Creative Commons license, and indicate if changes were made. The Creative Commons Public Domain Dedication waiver (http://creativecommons.org/publicdomain/zero/1.0/) applies to the data made available in this article, unless otherwise stated. 


\section{Background}

Obesity is a growing health problem worldwide. In the French Caribbean island of Guadeloupe, overweight and obesity were recently estimated at 23 and $9 \%$ respectively among children aged 5-14 years [1]. In this island, a high prevalence of diabetes $(8 \%)$ is also observed in the adult population. The causes of obesity are multifactorial but the main factor contributing to excessive weight gain in children should be the imbalance between energy intake and energy expenditure. The presence of obesity in childhood is associated with adverse effects on health including metabolic complications in which numerous cytokines and hormones are involved.

Among these cytokines, leptin and adiponectin, produced by adipose tissue, appear to play a role in glucose and lipid metabolism and energy homeostasis [2]. Ghrelin an orexigene hormone that also plays a role in energy metabolism by stimulating food intake and favoring weight and fat gain, has been recognized as an important regulator of glycemia and insulinemia [3].

Childhood obesity is a predictor of adult obesity and metabolic syndrome that are risk factors of morbidity and mortality [4-7] and, studies of long-term health consequences in adolescent males found that even moderate overweight is associated with excess mortality in adulthood [8].

Because lifestyle habits settle during childhood, it was recommended to precociously stop or prevent weight gain in overweight children notably by promoting lifestyle changes. These changes might also help to reduce obesity associated comorbidities.

Studies have analyzed the relationship between these hormones or cytokines and metabolic risk factors according to children's weight status $[7,9,10]$. But few studies have reported the concomitant variations of these factors after a lifestyle intervention [7, 11-13]. In addition, no data are available for these cytokines and metabolic risk markers in our children population.

Therefore, in the present study: 1) we evaluated the metabolic profile, including serum ghrelin, leptin and adiponectin levels, in schoolchildren classified as normal weight, overweight and obese and 2) we analyzed the potential changes in anthropometric and metabolic factors after a 1-year collaborative lifestyle intervention program.

\section{Methods}

\section{Study design}

We performed a cross-sectional analysis of basal data and a prospective study to evaluate after 1 year, the changes in children profiles in Guadeloupe Island (FWI).

\section{Study population}

In 2013, children from a middle school were invited to participate in the study. They were eligible if they were i) aged between 11 and 15 years, ii) affiliated to a social security scheme and iii) in good health conditions. Exclusion criteria included seizure disorders, diabetes, cardiovascular disease or pregnancy.

The study was approved by the Ethic Committee (South West - Overseas III, Bordeaux, France) in October 2012 and the French National Agency for Medecine and Health Products Safety Security (ANSM). Written informed consent, to participate in this study, was obtained from all children and parents.

\section{Study protocol}

At baseline, anthropometric and biochemical measurements were carried out in all children and, children and accompanying parents fulfilled questionnaires on lifestyle.

We conducted a 1-year lifestyle intervention program including 1) a nutritional information session presented, at the start of the study, by a nutritionist explaining healthy eating and nutrient needs to children and parents 2) Information on health risks for diseases related to lack of exercise and overweight 3) Encouragement for reduction of sedentary behaviors 4) Advices to achieve five hours per week of school physical education and/or physical activity outside of school and 5) Participation of parents.

The school usually provided three hours per week of physical education, supervised by physical education teachers.

Phone calls were made to maintain adherence to the program and, in voluntary children, anthropometric clinical
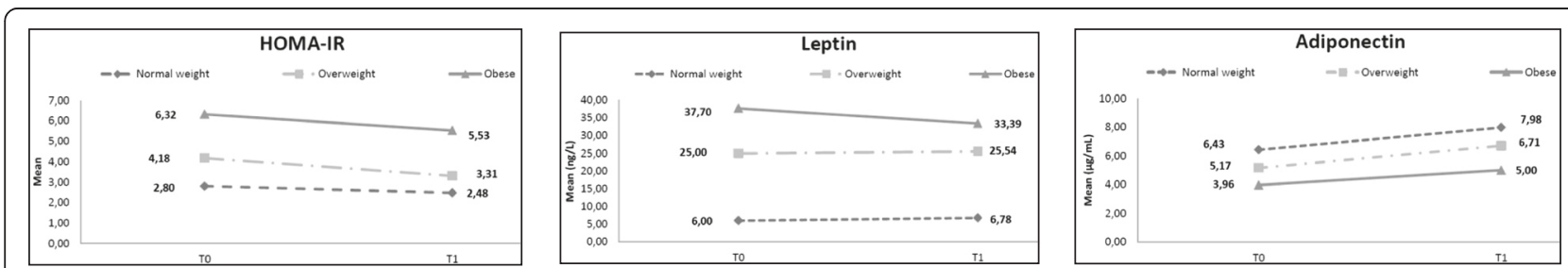

Fig. 1 Changes in HOMA-IR index, leptin and adiponectin levels in normal-weight, overweight and obese children after a 1 year of lifestyle intervention. HOMA-IR normal weight: $P=0.065$, overweight: $P=0.079$, obese: $P=0.011$. Leptin levels normal weight: $P=0.234$, overweight: $P=0.857$, obese: $P=0.008$. Adiponectin levels normal weight: $P=0.001$, overweight: $P=0.002$, obese: $P<0.001$ 
and biological parameters (except ghrelin concentrations) were evaluated after the 1-year lifestyle intervention.

\section{Data collection}

Clinical and biological examinations were performed at the referring Health Centre of Guadeloupe (AGREXAM). Participants were interviewed by a research Engineer and physicians using standard questionnaires that provided information on age, sex, anthropometric measurements, lifestyle and use of treatments.

Anthropometric measurements were performed by trained nurses. Height in centimeters $(\mathrm{cm})$ and weight in kilograms $(\mathrm{kg})$ were measured with participants standing without shoes and lightly clothed. The body mass index (BMI) was calculated as weight $/$ height $^{2}\left(\mathrm{~kg} / \mathrm{m}^{2}\right)$. The standard deviation score of body mass index (BMI $\mathrm{Z}$-score) was used to provide a standard indicator of relative adiposity [14] and was calculated as [(measured value - average value in the reference population)/standard deviation in the reference population] using a "Pediatric z-Score Calculator". Waist circumference (WC) in centimeters $(\mathrm{cm})$ was measured in a standing position at the navel level at minimal respiration and the waist-toheight ratio (WHtR) was calculated.

Systolic and diastolic blood pressure (SBP and DBP, respectively) were assessed using automated monitors after resting for at least $5 \mathrm{~min}$. The retained values were the average of two readings (left and right arms).

Pubertal stage was assessed according to Tanner [15]. Tanner stages 3, 4 and 5 defined pubertal/post-pubertal development.

\section{Laboratory measurements Blood sample analysis}

Blood samples were collected by venipuncture after an overnight fast. The biochemical analyses were performed in a single laboratory using the same methods.

Blood glucose level $(\mathrm{mmol} / \mathrm{L})$ was assessed using the glucose oxidase method. Serum lipid levels (mmol/L) were measured enzymatically.

Serum insulin levels $(\mu \mathrm{IU} / \mathrm{mL})$ were measured using the COBAS electro chemiluminescence immune assay test (Roche Diagnostics, Basel, Switzerland). The homeostasis model assessment to determined insulin resistance (HOMA-IR) was calculated using the following formula: [fasting insulin $(\mu \mathrm{IU} / \mathrm{mL}) \mathrm{x}$ fasting glucose $(\mathrm{mmol} / \mathrm{L}) / 22.5]$ [16].

Plasma samples were frozen at $-80{ }^{\circ} \mathrm{C}$ until measurements of ghrelin, leptin and adiponectin and assayed in duplicate. Total ghrelin (ng/L) was measured with RIA kit Merck-Millipore ${ }^{ø}$ (EZGRT-89 K), leptin ng/mL and total adiponectin $(\mu \mathrm{g} / \mathrm{mL})$ were measured with ELISA kits Biovendor ${ }^{\oplus}$ (RD191001100) and Alpco ${ }^{\circledR}$ (47ADPHUE-01) respectively. These measurements were made concomitantly for the samples collected at baseline and at one year (end of the study).

\section{Definition of factors}

Weight status The children were classified according to the definition of overweight and obesity by the International Obesity Task Force (IOTF), that provide age and sex specific cut off points in childhood (from 2-18 years), predicting the accepted adult cut off points of a BMI of 25 and $30 \mathrm{~kg} / \mathrm{m}^{2}$ (for overweight and obesity respectively) [17]. The three categories were defined as follows: normal weight with BMI $<$ IOTF- $25 \mathrm{~kg} / \mathrm{m}^{2}$, overweight with $\mathrm{BMI} \geq \mathrm{IOTF}-25 \mathrm{~kg} / \mathrm{m}^{2}$ and $\mathrm{BMI}<\mathrm{IOTF}$ $30 \mathrm{~kg} / \mathrm{m}^{2}$ and obesity.with BMI $\geq$ IOTF-30 kg/m ${ }^{2}$.

Abdominal obesity in children was defined as WHtR greater or equal to 0.5 [18].

Blood lipid abnormalities was defined as HDLcholesterol $<1.03$ or TG $\geq 1.7$ [18].

Insulin resistance was defined by a HOMA-IR > 3.16 [19].

\section{Statistical analysis}

Data are presented as numbers (percentages) for categorical variables and as means \pm standard deviations (SD) for continuous variables. The chi-squared test and ANCOVA with adjustment for age, sex were used to test percentage and mean differences between the three groups. Non parametric tests were used for comparison between data at baseline and 1-year.

The Pearson correlation test was used to study the relationships between serum ghrelin, leptin, adiponectin concentrations and the other continuous variables.

We also used the multivariate linear regressions in the overall study population to evaluate the associations of serum ghrelin, leptin and adiponectin as dependent variables and age, gender, weight status, Tanner stage and HOMA-IR as independent variables.

The IBM SPSS Statistics software version 21 was used for data analyses. All tests were two-sided and a $P$ value $<0.05$ was considered significant.

\section{Results}

\section{Analysis of parameters at baseline}

Overall 120 children of both sexes were enrolled in the study.

The accompanying parents were $80 \%$ women and $20 \%$ men. Forty four (37\%) of them were overweight/obese $\left(\mathrm{BMI}>25 \mathrm{~kg} / \mathrm{m}^{2}\right)$ and $29 \%$ were obese $\left(\mathrm{BMI} \geq 30 \mathrm{~kg} / \mathrm{m}^{2}\right)$. Family history of diabetes was noted in $50 \%$ of accompanying parents and $7 \%$ had personal history of diabetes.

The children were categorized into three groups: group 1 (G1: normal weight; $n=44$ ), group 2 (G2: overweight; $n=39$ ) and group 3 (G3: obeses; $n=37$ ). The characteristics of the study population according to weight status at baseline are presented in Table 1. 
Table 1 Characteristics of school-children 11 to 15 years according to weight status at baseline

\begin{tabular}{|c|c|c|c|c|c|}
\hline \multirow[t]{2}{*}{ Parameters } & Overall & Normal-weight & Overweight & Obese & $P$ \\
\hline & $n=120$ & $n=44$ & $n=39$ & $n=37$ & \\
\hline Sex (girls) & $59.2 \%$ & $52.3 \%$ & $69.3 \%$ & $56.8 \%$ & 0.270 \\
\hline Age (Years) & $12.4 \pm 1.1$ & $12.2 \pm 1.0$ & $12.5 \pm 1.2$ & $12.7 \pm 1.1$ & 0.130 \\
\hline $\mathrm{BMI}\left(\mathrm{Kg} / \mathrm{m}^{2}\right)$ & $24.1 \pm 6.1$ & $18.4 \pm 2.3^{* * *}$ & $24.2 \pm 1.6^{¥ ¥ ¥}$ & $30.1 \pm 4.9^{\S \S \S}$ & $<0.001$ \\
\hline BMI z-score & $1.08 \pm 1.18$ & $-0.17 \pm 1.04^{* * *}$ & $1.47 \pm 0.23^{¥ \neq \#}$ & $2.15 \pm 0.26^{\S \S \S}$ & $<0.001$ \\
\hline$W C(\mathrm{~cm})$ & $73.9 \pm 12.9$ & $62.9 \pm 7.1^{* * *}$ & $75.1 \pm 6.5^{¥ ¥ ¥}$ & $86.6 \pm 10.3^{\S \S \S}$ & $<0.001$ \\
\hline WHtR & $0.46 \pm 0.08$ & $0.39 \pm 0.04^{* * *}$ & $0.47 \pm 0.04^{¥ ¥ \neq}$ & $0.53 \pm 0.06^{\S \S \S}$ & $<0.001$ \\
\hline Abdominal obesity (\%) & $32.5 \%$ & $2.3 \%^{* * *}$ & $28.2 \%$ \% & $73.0 \% \$ \S \S$ & $<0.001$ \\
\hline Tanner stage $\geq 3$ (pubertal/post pubertal) & $92.5 \%$ & $90.9 \%$ & $92.3 \%$ & $94.6 \%$ & 0.82 \\
\hline $\mathrm{SBP}(\mathrm{mmHg})$ & $113 \pm 10$ & $110 \pm 9^{* *}$ & $113 \pm 8$ & $116 \pm 12$ & 0.015 \\
\hline $\mathrm{DBP}(\mathrm{mmHg})$ & $68 \pm 8$ & $66 \pm 6$ & $69 \pm 9$ & $70 \pm 7$ & 0.126 \\
\hline HDL-Cholesterol (mmol/L) & $1.32 \pm 0.35$ & $1.52 \pm 0.36^{* * *}$ & $1.22 \pm 0.28^{¥ \neq *}$ & $1.18 \pm 0.28^{\S \S \S}$ & $<0.001$ \\
\hline HDL-Cholesterol < 1.03 mmol/L(\%) & $21.7 \%$ & $11.4 \%$ & $28.2 \%^{*}$ & $27.0 \%$ & 0.261 \\
\hline LDL-Cholesterol (mmol/L) & $2.57 \pm 0.67$ & $2.55 \pm 0.72$ & $2.59 \pm 0.62$ & $2.57 \pm 0.69$ & 0.970 \\
\hline Triglycerides(mmol/L) & $0.78 \pm 0.44$ & $0.66 \pm 0.34^{* * *}$ & $0.74 \pm 0.35$ & $0.95 \pm 0.57$ & 0.007 \\
\hline Triglycerides $\geq 1.7$ mmol/L (\%) & $4.2 \%$ & $0 \%{ }^{*}$ & $5.1 \%$ & $8.1 \%$ & 0.287 \\
\hline Fasting blood glucose (mmol/L) & $4.8 \pm 0.4$ & $4.7 \pm 0.4$ & $4.8 \pm 0.4$ & $4.9 \pm 0.4$ & 0.019 \\
\hline Insulin $(\mu \mid \mathrm{U} / \mathrm{mL})$ & $21.3 \pm 12.9$ & $14.6 \pm 4.6^{* * *}$ & $21.7 \pm 13.9^{¥}$ & $28.8 \pm 14.3^{\S}$ & $<0.001$ \\
\hline HOMA-IR & $4.6 \pm 3.0$ & $3.5 \pm 1.1 * * *$ & $4.7 \pm 3.0^{*}$ & $6.5 \pm 3.5^{\S}$ & $<0.001$ \\
\hline HOMA-IR > $3.16(\%)$ & $65.0 \%$ & $38.6 \% \%^{* * *}$ & $71.8 \%{ }^{¥}$ & $89.2 \%$ & $<0.001$ \\
\hline Ghrelin (ng/L) & $1379 \pm 488$ & $1541 \pm 514^{*}$ & $1355 \pm 440$ & $1221 \pm 457$ & 0.012 \\
\hline Leptin ng/mL & $22.9 \pm 20.4$ & $8.5 \pm 6.1^{* * *}$ & $23.6 \pm 12.6^{¥ ¥ \neq}$ & $39.6 \pm 22.9^{\S \S \S}$ & $<0.001$ \\
\hline Adiponectin $\mu \mathrm{g} / \mathrm{mL}$ & $5.4 \pm 2.6$ & $6.8 \pm 2.8^{* * *}$ & $4.9 \pm 2.2^{¥ ¥}$ & $4.1 \pm 1.8$ & $<0.001$ \\
\hline
\end{tabular}

Data in this table are mean \pm SD and column percentage

$B M I$ body mass index, WC waist circumference, $W H t R$ wait-to-height ratio, $S B P$ systolic blood pressure, $D B P$ diastolic blood pressure, $H D L-C$ high density lipoprotein cholesterol, LDL-C low density lipoprotein cholesterol, TG triglycerides, HOMA-IR homeostasis model assessment-insulin resistance

$P$ : $P$ value for global comparison between the three groups

Comparison for normal-weight vs obese children ${ }^{*} P<0.05$, ${ }^{* *} P<0.01$, *** $P<0.001$

Comparison for normal-weight vs overweight children ${ }^{¥} P<0.05,{ }^{\sharp ¥} P<0.01, \stackrel{¥}{*} P<0.001$

Comparison for overweight vs obese children: ${ }^{\S} P<0.05,{ }^{\S \S} P<0.01,{ }^{\S \S} P<0.001$

All $p$-values are in italic and significant $p$-value are in bolditalic

The mean age of the study population was $12.4 \pm$ 1.1 years and $59 \%$ were girls. Tanner stages were distributed as follows: stage 2: $7.5 \%$, stage 3: $58.3 \%$, stage 4 : $30 \%$ and stage 5: $4.2 \%$.

Overall, $92.5 \%$ of the children had a tanner stage $\geq 3$ (pubertal/post pubertal development) with no significant difference between the three groups $(P=0.82$, Table 1$)$. The frequency of children eating at school canteen was higher in normal weight $(53 \%)$ than in overweight $(28 \%)$ and obese $(30 \%)$ children; $(P=0.027)$, (data not shown).

In accordance with the design of the study, all the anthropometric parameters (BMI, BMI z-score, WC and $\mathrm{WC} /$ height) were significantly different between the three groups $(P<0.001$ for all parameters). Obese children had higher SBP $(P=0.015)$, triglycerides $(P=0.007)$, fasting blood glucose $(P=0.019)$, insulin $(P<0.001)$ and leptin levels $(P<0.001)$, whereas they had lower HDL-C $(P<0.001)$, ghrelin $(P=0.001)$ and adiponectin levels
$(P<0.001)$ than the other groups. Abdominal obesity and insulin resistance were also more frequently found in the obese group ( $P<0.001$ for both).

Leptin levels were higher in girls than in boys in the overall study sample (27 vs $16 \mathrm{ng} / \mathrm{mL} ; P=0.004$ ) whereas no significant gender differences were found for adiponectin $(P=0.164)$ and ghrelin levels $(P=0.110)$.

The correlations between leptin, ghrelin, adiponectin levels and the other continuous variables: anthropometric parameters, blood lipids and insulin levels, among boys and among girls respectively are presented in Table 2a and b. Leptin, ghrelin, adiponectin levels were significantly correlated with the three anthropometric parameters (BMI z score, WC, WHt) in both genders except for ghrelin in girls. Concerning FBG and blood lipid parameters, in boys, significant correlations were found except for ghrelin with TG levels, for leptin with FBG and LDL-C and for adiponectin with FBG, LDL-C and TG levels. In girls, no significant correlation was 
Table 2 Correlations between Ghrelin, Adiponectin and Leptin and anthropometric and metabolic parameters among school-children by gender 11 to 15 years at baseline

\begin{tabular}{|c|c|c|c|c|c|c|c|c|c|c|c|c|}
\hline \multirow[t]{3}{*}{ Parameters } & \multicolumn{6}{|c|}{ 2a: Boys } & \multicolumn{6}{|c|}{ 2b: Girls } \\
\hline & \multicolumn{2}{|c|}{ Ghrelin (ng/L) } & \multicolumn{2}{|c|}{ Leptin(ng/mL) } & \multicolumn{2}{|c|}{ Adiponectin ( $\mu \mathrm{g} / \mathrm{mL})$} & \multicolumn{2}{|c|}{ Ghrelin (ng/L) } & \multicolumn{2}{|c|}{ Leptin(ng/mL) } & \multicolumn{2}{|c|}{ Adiponectin $(\mu \mathrm{g} / \mathrm{mL})$} \\
\hline & $r$ & $P$ & $r$ & $P$ & $r$ & $P$ & $r$ & $P$ & $r$ & $P$ & $r$ & $P$ \\
\hline BMl z-score & -0.59 & $<0.001$ & 0.70 & $<0.001$ & -0.40 & 0.005 & -0.08 & 0.523 & 0.66 & $<0.001$ & -0.40 & 0.001 \\
\hline$W C(\mathrm{~cm})$ & -0.64 & $<0.001$ & 0.78 & $<0.001$ & -0.46 & 0.001 & -0.12 & 0.313 & 0.79 & $<0.001$ & -0.46 & $<0.001$ \\
\hline $\mathrm{WH} \mathrm{tR}$ & -0.51 & $<0.001$ & 0.85 & $<0.001$ & -0.36 & 0.013 & -0.10 & 0.399 & 0.73 & $<0.001$ & -0.50 & $<0.001$ \\
\hline $\mathrm{FBG}(\mathrm{mmol} / \mathrm{L})$ & -0.37 & 0.001 & 0.25 & 0.087 & -0.10 & 0.483 & 0.07 & 0.587 & 0.36 & 0.003 & -0.32 & 0.006 \\
\hline $\mathrm{HDL}-\mathrm{C}(\mathrm{mmol} / \mathrm{L})$ & 0.41 & 0.005 & -0.36 & 0.013 & 0.57 & $<0.001$ & 0.16 & 0.190 & -0.39 & 0.001 & 0.46 & $<0.001$ \\
\hline LDL-C (mmol/L) & 0.36 & 0.014 & 0.28 & 0.058 & 0.11 & 0.485 & 0.17 & 0.149 & -0.05 & 0.707 & -0.02 & 0.881 \\
\hline $\mathrm{TG}(\mathrm{mmol} / \mathrm{L})$ & -0.10 & 0.492 & 0.53 & $<0.001$ & -0.18 & 0.238 & 0.21 & 0.076 & 0.25 & 0.038 & -0.07 & 0.585 \\
\hline Insulin $(\mu \mathrm{U} / \mathrm{mL})$ & -0.52 & $<0.001$ & 0.55 & $<0.001$ & -0.44 & 0.002 & -0.13 & 0.267 & 0.47 & $<0.001$ & -0.35 & 0.003 \\
\hline HOMA-IR index & -0.53 & $<0.001$ & 0.57 & $<0.001$ & -0.44 & 0.002 & -0.11 & 0.357 & 0.50 & $<0.001$ & -0.36 & 0.003 \\
\hline
\end{tabular}

$B M I$ body mass index, $W C$ waist circumference, $W H t R$ wait-to-height ratio, FBG Fasting blood glucose, $H D L-C$ high density lipoprotein cholesterol, $L D L-C$ low density lipoprotein cholesterol, TG triglycerides, HOMA-IR homeostasis model assessment-insulin resistance

All $p$-values are in italic and significant $p$-value are in bolditalic

found for ghrelin with the 4 parameters, for leptin with LDL-C and for adiponectin with LDL-C and TG.

High significant correlations were also noted between ghrelin, leptin and adiponectin levels with insulin levels and HOMA-IR in both genders except for ghrelin levels in girls.

All anthropometric parameters were positively correlated with insulin and HOMA-IR in both genders (data not shown).

In considering the weight status of accompanying parents, insulin resistance (HOMA IR > 3.16) was noted in $61 \%$ of children from parents with normal weight and in $70 \%$ of children from overweight or obese parents (data not shown).

Table 3 presents the results of the multivariate linear regression analyses exploring the associations of ghrelin, adiponectin and leptin with age, gender, weight status, HOMA-IR and tanner stage as independent variables, at baseline.
In model 1, for ghrelin levels, no significant association was noted with the five variables but association with HOMA-IR was nearly significant $(P=0.070)$. The model accounted for $15 \%\left(r^{2}=0.15\right)$ of the variability in ghrelin levels.

In model 2, for adiponectin levels, significant negative associations were noted with overweight $(P=0.002)$, obesity $(P=0.001)$ and HOMA-IR $(P=0.010)$ and the model accounted for $26 \%\left(r^{2}=0.26\right)$ of the variability in adiponectin levels.

In model 3, for leptin levels, significant positive associations were noted with gender $(P=0.011)$, overweight $(P<0.001)$, obesity $(P<0.001)$ and HOMA-IR $(P=0.002)$. The average increase in leptin levels was $7.9 \mathrm{ng} / \mathrm{dL}$ for gender (girls), $13.9 \mathrm{ng} / \mathrm{dL}$ for overweight, $26.4 \mathrm{ng} / \mathrm{dL}$ for obesity and $1.50 \mathrm{ng} / \mathrm{dL}$ for each unit of HOMA-IR. This multivariate model accounted for $58 \%\left(r^{2}=0.58\right)$ of the variability in leptin levels.

Table 3 Multivariate linear regression for Ghrelin, Adiponectin and Leptin levels in 120 schoolchildren 11 to 15 years, at baseline

\begin{tabular}{|c|c|c|c|c|c|c|}
\hline \multirow[b]{3}{*}{ Variables } & \multirow{2}{*}{\multicolumn{2}{|c|}{$\begin{array}{l}\text { Model } 1 \text { Ghrelin (ng/L) } \\
\qquad \begin{array}{l}r^{2}=0.15 \\
\text { Adjusted } r^{2}=0.11\end{array}\end{array}$}} & \multirow{2}{*}{\multicolumn{2}{|c|}{$\begin{array}{c}\text { Model } 2 \text { - Adiponectin }(\mu \mathrm{g} / \mathrm{mL}) \\
r^{2}=0.26 \\
\text { Adjusted } r^{2}=0.22\end{array}$}} & \multirow{2}{*}{\multicolumn{2}{|c|}{$\begin{array}{c}\text { Model } 3 \text { Leptin }(\mathrm{ng} / \mathrm{mL}) \\
r^{2}=0.58 \\
\text { Adjusted } r^{2}=0.56\end{array}$}} \\
\hline & & & & & & \\
\hline & nSRC (SE) & $P$ & $\mathrm{nSRC}(\mathrm{SE})$ & $P$ & $\mathrm{nSRC}(\mathrm{SE})$ & $P$ \\
\hline Age (Years) & $-113(88)$ & 0.205 & $0.44(0.44)$ & 0.318 & $3.18(2.61)$ & 0.226 \\
\hline Gender (girls) & $-71(102)$ & 0.488 & $0.68(0.51)$ & 0.187 & $7.87(3.02)$ & 0.010 \\
\hline \multicolumn{7}{|l|}{ Weight Status } \\
\hline Overweight & $-81(109)$ & 0.455 & $-1.67(0.53)$ & 0.002 & $13.88(3.15)$ & $<0.001$ \\
\hline Obese & $-164(119)$ & 0.171 & $-2.10(0.59)$ & 0.001 & $26.36(3.49)$ & $<0.001$ \\
\hline Tanner stage 2 to 5 & $52(135)$ & 0.689 & $-0.45(0.68)$ & 0.508 & $-0.73(4.01)$ & 0.856 \\
\hline HOMA-IR & $-29(16)$ & 0.071 & $-0.21(0.08)$ & 0.010 & $1.50(0.47)$ & 0.002 \\
\hline
\end{tabular}

nSRC non standardized regression coefficient, SE standard error, HOMA-IR homeostasis model assessment forinsulin resistance All $p$-values are in italic and significant $\mathrm{p}$-value are in bolditalic 
No significant average change in ghrelin, leptin and adiponectin levels was noted in relation with tanner stage.

Table 4 presents changes in clinical and metabolic parameters at one year of follow-up. Of the 120 children who participated to the study at baseline, 83 have accepted to undergo evaluation for clinical and biological parameters after one year (28 in normal weight, 28 in overweight, and 27 in obese children).

Mean BMI z-score significantly decreased in overweight (1.47 to $1.33 ; P=0.021)$ and obese children $(2.18$ to $2.08 ; P=0.008$ ) whereas, no significant change was noted in the normal weight group $(-0.10$ to $-0.16 ; P=0.446)$ (Table 4).

Concerning the metabolic parameters, significant decreases were observed in normal weight children for LDL-C $(P=0.018)$ and insulin levels $(P=0.048)$. The HDL-C levels decreased in this group $(P<0.001)$ but remained higher than in the other groups. Fasting blood glucose $(P=0.047)$, LDL-C $(P=0.015)$ and insulin levels $(P=0.019)$ improved in overweight children. In obese children, significant improvements were also observed in FBG $(P=0.002)$, insulin levels $(P=0.019)$ and HOMA-IR $(P=0.011)$. Significant rises in adiponectin levels were observed in normal weight overweight and obese children $(P=0.001, P=0.002, P<0.001$ respectively). Leptin levels remained unchanged at 1 year of follow-up in normal weight and overweight children but decreased significantly in obese children $(P=0.008)$. Table 4 and fig. 1 present changes in clinical and metabolic parameters at one year of follow-up.

Combining the results of the three groups, a nearly significant correlation was found between changes in BMI $\mathrm{z}$-score, and changes in leptin concentrations $(r=0.20$; $P=0.060)$. This positive correlation was significant in the obese group $(r=0.39 ; P=0.049)$. Conversely no significant correlation was found between changes in BMI $\mathrm{z}$-score, and both changes in HOMA-IR and adiponectin levels (data not shown).
We evaluated the frequencies of children undergoing concomitant changes in the three metabolic parameters at 1 year (decrease HOMA IR and leptin levels and increase adiponectin levels) and we found a frequency of $27 \%$ in children from parents with normal weight and of $37 \%$ in children from overweight or obese parents.

\section{Discussion}

The current study is the first to evaluate the metabolic profile in overweight and obese Guadeloupean children. Obesity was associated with an adverse metabolic profile including, high frequencies of abdominal obesity (73\%) and of insulin resistance ( $89 \%$ ) highlighting the risk for development of type 2 diabetes and future cardiovascular complications in adulthood $[4,20]$. These obese children also exhibited, at baseline, the highest values for triglycerides and leptin levels and the lowest values for HDL-cholesterol, ghrelin and adiponectin levels. In addition, leptin levels appeared to have a stronger relationship with weight status and HOMA-IR than ghrelin and adiponectin at baseline which is in favor of a role of leptin in body weight regulation [21]. Our 1-year collaborative lifestyle intervention, led to improvements in BMI z-score and in most of the metabolic parameters particularly in the obese children. The results, after the intervention, also showed that changes in BMI z-score correlated with changes in leptin levels. Leptin levels decreased significantly only in the obese group whereas adiponectin concentrations increased in normal weight, overweight and obese children.

\section{Anthropometric parameters}

All the anthropometric parameters (WC, WHtR and BMI Z-score) were significantly correlated with ghrelin, leptin and adiponectin except in girls in whom no correlation with ghrelin was observed. Abdominal obesity, defined in children as WHtR greater than 0.5 [18], has

Table 4 Clinical and biological parameters in 83 children at baseline and after 1 year of a lifestyle intervention program

\begin{tabular}{|c|c|c|c|c|c|c|c|c|c|}
\hline \multirow{2}{*}{ Parameters } & \multicolumn{3}{|c|}{ Normal-weight $(n=28)$} & \multicolumn{3}{|c|}{ Overweight $(n=28)$} & \multicolumn{3}{|c|}{ Obese $(n=27)$} \\
\hline & Baseline & T1-year & $P$ & Baseline & T1-year & $P$ & Baseline & T1-year & $P$ \\
\hline BMI z-score & $-0.10 \pm 1.03$ & $-0.16 \pm 0.85$ & 0.446 & $1.47 \pm 0.24$ & $1.33 \pm 0.44$ & 0.021 & $2.18 \pm 0.27$ & $2.08 \pm 0.40$ & 0.008 \\
\hline $\mathrm{FBG}(\mathrm{mmol} / \mathrm{L})$ & $4.67 \pm 0.38$ & $4.63 \pm 0.34$ & 0.690 & $4.82 \pm 0.42$ & $4.69 \pm 0.42$ & 0.047 & $4.95 \pm 0.40$ & $4.69 \pm 0.35$ & 0.002 \\
\hline $\mathrm{HDL}-\mathrm{C}(\mathrm{mmol} / \mathrm{L})$ & $1.59 \pm 0.36$ & $1.45 \pm 0.31$ & $<0.001$ & $1.21 \pm 0.28$ & $1.18 \pm 0.21$ & 0.425 & $1.19 \pm 0.29$ & $1.14 \pm 0.28$ & 0.248 \\
\hline $\mathrm{LDL}-\mathrm{C}(\mathrm{mmol} / \mathrm{L})$ & $2.61 \pm 0.75$ & $2.37 \pm 0.66$ & 0.018 & $2.68 \pm 0.59$ & $2.48 \pm 0.48$ & 0.015 & $2.46 \pm 0.59$ & $2.43 \pm 0.47$ & 0.410 \\
\hline $\mathrm{TG}(\mathrm{mmol} / \mathrm{L})$ & $0.55 \pm 0.26$ & $0.56 \pm 0.24$ & 0.945 & $0.78 \pm 0.40$ & $0.73 \pm 0.39$ & 0.682 & $0.86 \pm 0.32$ & $0.80 \pm 0.36$ & 0.254 \\
\hline Insulin $(\mu \mathrm{U} / \mathrm{mL})$ & $13.4 \pm 3.6$ & $11.8 \pm 6.1$ & 0.048 & $19.9 \pm 12.5$ & $15.8 \pm 7.0$ & 0.019 & $28.4 \pm 13.7$ & $26.2 \pm 17.7$ & 0.019 \\
\hline HOMA-IR index & $2.80 \pm 0.86$ & $2.48 \pm 1.37$ & 0.065 & $4.18 \pm 3.04$ & $3.31 \pm 1.56$ & 0.079 & $6.32 \pm 3.19$ & $5.53 \pm 3.95$ & 0.011 \\
\hline Leptin (ng/mL) & $6.0 \pm 5.19$ & $6.78 \pm 1.9$ & 0.234 & $25.0 \pm 13.0$ & $25.5 \pm 18.1$ & 0.857 & $37.7 \pm 22.5$ & $33.4 \pm 24.2$ & 0.008 \\
\hline Adiponectin $(\mu \mathrm{g} / \mathrm{mL})$ & $6.43 \pm 2.51$ & $7.98 \pm 3.56$ & 0.001 & $5.17 \pm 2.39$ & $6.71 \pm 2.77$ & 0.002 & $3.96 \pm 1.84$ & $5.0 \pm 2.41$ & $<0.001$ \\
\hline
\end{tabular}

FBG fasting blood glucose, $B M I$ body mass index, WC waist circumference, HOMA-IR homeostasis model assessment for insulin resistance All $p$-values are in italic and significant $p$-value are in bolditalic 
been associated in adulthood with cardio vascular complications [18] and was found in $2.3 \%$ of normal weight, $28.2 \%$ of overweight and $73 \%$ of our obese children.

In a recent review, the authors recommended to pay more attention to abdominal obesity in children and adolescents because central body fat deposition increases the risk of cardio-metabolic risk factors, whatever the definition used for abdominal obesity and whatever the methods used for anthropometric measurements, [22].

\section{Metabolic profile, ghrelin and cytokines}

The lowest HDL-C concentrations, the highest triglycerides and FBG concentrations and the highest values for HOMA-IR index were observed in the obese children. It is well known that obesity is associated with comorbidities such as dyslipidemia, hypertension, insulin resistance $[20,23]$ and with early indication of atherosclerosis $[24,25]$. We also observed high frequencies of insulin resistance (defined as HOMA-IR greater than 3.16) in obese (89\%), overweight (72\%) and normal weight children (39\%). Insulin sensitivity index was previously reported lower in black compared with white adolescents suggesting a more diabetic profile in the first group [26]. In our general population in which most people are of African ancestry and diabetes is highly prevalent (8\%), the results observed in children and adolescents highlight their high risk of metabolic complications. This risk is probably increased due to children family history showing $50 \%$ of overweight and $7 \%$ of diabetes in accompanying parents.

Despite ghrelin levels were not significantly associated with HOMA-IR in the linear regression (Table 3), the hormone has been recognized as an important regulator of energy metabolism and serves as a physiological regulator of insulinemia and glycemia [3].

Adipose tissue is considered as an endocrine organ producing several proteins (including leptin and adiponectin) with important biological activity and, the adipocyte plays a central role in the balance, or imbalance, of metabolic homeostasis [27]. Adiponectin levels were the lowest and leptin levels the highest in the obese group. Numerous studies described significant negative correlations between adiponectin and the parameters of obesity. Low adiponectin concentrations which has been previously associated with coronary artery disease in the adult population of Guadeloupe [28] correlated with high plasma insulin levels and adverse blood lipid profile in the present study in children. Lower adiponectin levels in obesity were also associated with chronic inflammation, endothelial dysfunction, and insulin resistance [29, 30]. The three multivariate linear regression models for ghrelin, adiponectin and leptin levels, as dependent variables (Table 3) and age, gender, weight status, tanner stage and HOMA-IR as independent variables, highlighted the strong associations of leptin and adiponectin levels with body weight and insulin resistance at baseline. The model accounted for $58 \%$ of variability in leptin levels compared with 26 and $15 \%$ of variability in adiponectin and in ghrelin levels respectively. Leptin levels increased significantly by $1.50 \mathrm{ng} / \mathrm{ml}$ for each unit of HOMA-IR. These strong relationships were also reported in a study on 321 children (109 normal, 212 obese) aged 6-12 years, analysing leptin, ghrelin, adiponectin levels [10]. In this study, leptin was found as the most sensitive adipokine marker for predicting the accumulation of cardiovascular risk factors and the presence of metabolic syndrome [10]. The gender difference for leptin levels, previously reported in children and adults [7, 21,31-33], was also found in our study with girls exhibiting higher values than boys. This difference might reflect the higher ratio of subcutaneous to visceral fat in women than in men since serum leptin is strongly related to subcutaneous fat mass [21]. But, other factors besides adiposity, such as sex steroids, might play a role in this gender difference [21].

Leptin administration has been demonstrated to reduce obesity in leptin-deficient $o b / o b$ mice [34] and, to decrease food intake, body weight, increase energy expenditure and improve metabolic status in leptin deficient subjects [35, 36]. But, in most individuals, serum leptin levels are positively correlated with BMI and with indexes of obesity. Thus, the concept of leptin resistance has emerged to explain the paradoxical elevated leptin levels in obesity. Several mechanisms have been suggested to explain this leptin resistance, notably the impaired transport of leptin across blood brain barrier [37], or decrease of hypothalamic leptin receptor expression [38] as well as attenuation of leptin signaling by protein tyrosine phosphatases [39].

The mechanism by which increased body fat cause increased metabolic comorbidities is not really known. It was suggested that excess adipose tissue contribute to a state of chronic inflammation which promotes development of insulin resistance as well as other metabolic complications [40]. Leptin and adiponectin show opposite effects on inflammation and insulin resistance. While high leptin levels increase the expression of pro-inflammatory and pro-angiogenic factors [41] adiponectin, improves peripheral insulin sensitivity, and induces the production of anti-inflammatory cytokines [42].

\section{Changes in anthropometric and metabolic parameters after 1 year follow-up}

In this study population without significant differences between groups in age, sex and Tanner stage distributions, we observed after the 1-year lifestyle intervention, a reducing in BMI z-score in overweight and obese children and improvements in most of the metabolic parameters with greater benefits in the obese group. This group showed 
significant improvements in fasting insulin levels, HOMA-IR, leptin and adiponectin levels. These results are interesting since increase of insulin levels, HOMAIR and leptin levels would be expected after one year with increasing age or puberty. In fact, in EarlyBird, a prospective cohort study of healthy children, insulin resistance started to rise in mid-childhood, and HOMAIR rose, almost linearly, from age of 8 [43]. Ballabriga A et al. reported that both prepubertal boys and girls showed a progressive increase of leptin levels during the years prior to the onset of puberty and until Tanner's stage 11 [44].

Serum leptin is believed to play a role in obesity but, although leptin levels were strongly associated with HOMA-IR and weight status at baseline, in the present study, significant decrease in leptin levels were noted only in obese children at one year follow-up. In other studies, after lifestyle intervention or after exercise training program, leptin levels decreased [45] or remained unchanged $[7,13,46]$. In addition, leptin levels increased in children without weight loss in one of these studies [13].

At one year of follow-up, adiponectin levels increased significantly in the three groups although normal weight children showed no significant reduction of BMI zscore. Cambuli et al. evaluated adipokines levels but also fat-free mass and fat mass, before and after 1 year of lifestyle intervention in 104 overweight and obese children [13]. In this study, adiponectin in particular increased from baseline at the end of the study. In addition, the authors found that changes in adiponectin were significantly and independently associated with changes in percent fat mass and that, even those children who did not lose weight obtained a significant reduction in percent fat mass [13]. It was previously reported that high adiponectin concentrations predicted lower prevalence of type 2 diabetes in obese Mexican children [47] and that low adiponectin concentrations were associated with increased risk of type 2 diabetes in adults [48, 49]. But, high leptin levels were not associated with risk of incident type 2 diabetes in an Aboriginal Canadian population [48]. In our population having a high prevalence of type 2 diabetes, adiponectin could be a tool for monitoring overweight or obese children having marked insulinresistance.

\section{Implications in prevention of overweight in children}

The efficiency of lifestyle intervention for childhood obesity has been previously reported with changes in body weight but also changes in metabolic parameters. Moreover, obesity treatment programs are more effective in reducing overweight in children if parents are involved. The positive effect of eating in school canteen should be highlighted. Our children with normal weight ate more frequently in school canteen than the other groups. In fact, it is a beneficial factor since the menus follow the recommendations designed to lower fat and sugar and increase vegetables and fruit in meals. In addition, the children can take advantage of the infrastructure for physical activity and sport activities proposed by the school.

\section{Limitation and strengths of the study}

The potential limitations of our study include i) the small sample size even if other lifestyle intervention studies were conducted on small sample sizes [7, 12, 13] and ii) the absence of controls groups (without lifestyle intervention) that did not let us draw any causality link between the lifestyle intervention and the improvement of the parameters studied.

Nevertheless, the present study has a number of strengths. i) the children were healthy, comparable between groups for age, sex and Tanner stage distributions and presented no associated diseases that could influence the metabolic profile, ii) the use of traditional markers for metabolic disease (ie, lipid profile, insulin levels, HOMA-IR) and the measurement for the first time of adiponectin, leptin and ghrelin concentrations in a sample of Guadeloupean children and iii) the providing of data on changes in metabolic parameters at the end of the lifestyle intervention.

\section{Conclusion}

Abdominal obesity and insulin resistance, that could precede other metabolic complications, were frequent in obese children highlighting their high risk of obesity and type 2 diabetes in adulthood. The 1-year collaborative lifestyle intervention, involving children parents and teachers seems rather beneficial, notably in obese children, with improvements in body composition, insulin, leptin and adiponectin levels. This improvement is probably the result of different factors including the fight against sedentary lifestyles and changes in eating habits in the families.

These results might be used to encourage parents to participate in prevention programs against overweight. In addition, sensitization of families (children and accompanying) on health risks related to sedentary behaviors must be continuous.

\footnotetext{
Abbreviations

BMI: Body mass index; BMI z-score: Standard deviation score of body mass index; BP: Blood pressure; FBG: Fasting blood glucose; HDL-C: High-density lipoprotein Cholesterol; HOMA-IR: Homeostasis model assessment for insulin resistance; IOTF: International Obesity Task Force; LDL-C: Low-density lipoprotein Cholesterol; MetS: Metabolic syndrome; SD: Standard deviation; TG: Triglycerides; WC: Waist circumference; WHtR: Waist-to-height ratio.
}

Competing interests

The authors declare that they have no competing interests. 


\section{Authors' contributions}

LF was responsible for the study design. JC and JP contributed to acquisition of clinical data. EBA and JML were responsible for the laboratory measurements. CR and LF performed the data analysis, interpreted the data and drafted the manuscript. EBA, LL, JD, JC, JP and JML revised the manuscript content. All authors read and approved the final manuscript.

\section{Authors' information}

CR is a PhD student in the research team ECM/LAMIA EA4540.

\section{Acknowledgements}

We would like to acknowledge all children and parents who participated in the study. Great thanks to the nurses and physicians of the AGREXAM Health Centre, to the teachers of physical education, to Mrs L Nesty, the headmaster of the middle school named "College Saint John Perse" located in Guadeloupe and to Dr M Meissonnier, the head of the Health Centre. We also thank Mrs Francine Mathis for language assistance.

\section{Funding}

This study was partly supported by grants from the University Hospital of Guadeloupe.

\section{Author details}

${ }^{1}$ Equipe de recherche sur le Risque Cardio métabolique, ECM/LAMIA EA4540, Université des Antilles et de la Guyane, Guadeloupe, France. ${ }^{2}$ Sorbonne Université, UPMC Univ Paris 06, UMR_S 1166, ICAN, F-75005 Paris, France. ${ }^{3}$ INSERM, UMR_S 1166, ICAN, F-75005 Paris, France. ${ }^{4}$ AP-HP, Hôpital Pitié-Salpêtrière-Charles Foix, Biochimie Endocrinienne et Oncologique, F-75651 Paris, Cedex, France. ${ }^{5}$ Service de cardiologie, CHU de Guadeloupe, 97159 Pointe-à-Pitre, Guadeloupe, France. ${ }^{6}$ Réseau GRANDIR, Guadeloupe, France. ${ }^{7}$ Centre d'Examens de Santé, AGREXAM, Guadeloupe, France. ${ }^{8}$ Département de Santé Publique, CHU, 97159 Pointe-à-Pitre, Guadeloupe, FWI, France.

\section{Received: 22 July 2015 Accepted: 9 November 2015}

\section{Published online: 14 November 2015}

\section{References}

1. Daigre $\mathrm{L}$, Atallah A, Boissin $\mathrm{L}$, Jean-Baptiste $\mathrm{G}$, Kangambega $\mathrm{P}$, Chevalier $\mathrm{H}$, et al. The prevalence of overweight and obesity, and distribution of waist circumference, in adults and children in the French Overseas Territories: the PODIUM survey. Diabetes Metab. 2012;38:404-11.

2. Korner A, Kratzsch J, Gausche R, Schaab M, Erbs S, Kiess W. New predictors of the metabolic syndrome in children-role of adipocytokines. Pediatr Res. 2007;61:640-5.

3. Gil-Campos M, Aguilera CM, Canete R, Gil A. Ghrelin: a hormone regulating food intake and energy homeostasis. Br J Nutr. 2006;96:201-26.

4. Chen F, Wang Y, Shan X, Cheng H, Hou D, Zhao X, et al. Association between childhood obesity and metabolic syndrome: evidence from a large sample of Chinese children and adolescents. PLoS One. 2012;7:e47380.

5. Liu W, Lin R, Liu A, Du L, Chen Q. Prevalence and association between obesity and metabolic syndrome among Chinese elementary school children: a school-based survey. BMC Public Health. 2010;10:780.

6. Lloyd $\sqcup$, Langley-Evans SC, McMullen S. Childhood obesity and risk of the adult metabolic syndrome: a systematic review. Int J Obes (Lond). 2012;36:1-11.

7. Pedrosa C, Oliveira BM, Albuquerque I, Simoes-Pereira C, Vaz-de-Almeida MD, Correia F. Obesity and metabolic syndrome in 7-9 years-old Portuguese schoolchildren. Diabetol Metab Syndr. 2010;2:40.

8. Must A. Morbidity and mortality associated with elevated body weight in children and adolescents. Am J Clin Nutr. 1996;63:445S-7S.

9. McFarlin BK, Johnson CA, Moreno JP, Foreyt JP. Mexican American children have differential elevation of metabolic biomarkers proportional to obesity status. J Pediatr Gastroenterol Nutr. 2013;57:718-21.

10. Yoshinaga M, Sameshima K, Tanaka Y, Wada A, Hashiguchi J, Tahara H, et al. Adipokines and the prediction of the accumulation of cardiovascular risk factors or the presence of metabolic syndrome in elementary school children. Circ J. 2008;72:1874-8.

11. Balagopal PB, Gidding SS, Buckloh LM, Yarandi HN, Sylvester JE, George DE, et al. Changes in circulating satiety hormones in obese children: a randomized controlled physical activity-based intervention study. Obesity (Silver Spring). 2010;18:1747-53.
12. Bluher S, Panagiotou G, Petroff D, Markert J, Wagner A, Klemm T, et al. Effects of a 1-year exercise and lifestyle intervention on irisin, adipokines, and inflammatory markers in obese children. Obesity (Silver Spring). 2014;22:1701-8

13. Cambuli VM, Musiu MC, Incani M, Paderi M, Serpe R, Marras V, et al. Assessment of adiponectin and leptin as biomarkers of positive metabolic outcomes after lifestyle intervention in overweight and obese children. J Clin Endocrinol Metab. 2008;93:3051-7.

14. Cole TJ, Faith MS, Pietrobelli A, Heo M. What is the best measure of adiposity change in growing children: BMI, BMI \%, BMl z-score or BMI centile? Eur J Clin Nutr. 2005;59:419-25.

15. Tanner JM. Growth and maturation during adolescence. Nutr Rev. 1981;39:43-55.

16. Cutfield WS, Jefferies CA, Jackson WE, Robinson EM, Hofman PL. Evaluation of HOMA and QUICKI as measures of insulin sensitivity in prepubertal children. Pediatr Diabetes. 2003;4:119-25.

17. Cole TJ, Bellizzi MC, Flegal KM, Dietz WH. Establishing a standard definition for child overweight and obesity worldwide: international survey. BMJ. 2000; 320:1240-3.

18. Varda NM, Gregoric A. Metabolic syndrome in the pediatric population: a short overview. Pediatr Rep. 2009;1:e1.

19. Keskin M, Kurtoglu S, Kendirci M, Atabek M, Yazici C. Homeostasis model assessment is more reliable than the fasting glucose/insulin ratio and quantitative insulin sensitivity check index for assessing insulin resistance among obese children and adolescents. Pediatrics. 2005;115:e500-e3.

20. Steinberger J, Daniels SR. Obesity, insulin resistance, diabetes, and cardiovascular risk in children: An American heart association scientific statement from the atherosclerosis, hypertension, and obesity in the young committee (council on cardiovascular disease in the young) and the diabetes committee (council on nutrition, physical activity, and metabolism). Circulation. 2003;107:1448-53.

21. Wauters M, Considine RV, Van Gaal LF. Human leptin: from an adipocyte hormone to an endocrine mediator. Eur J Endocrinol. 2000;143:293-311.

22. Kelishadi R, Mirmoghtadaee $P$, Najafi $H$, Keikha M. Systematic review on the association of abdominal obesity in children and adolescents with cardio-metabolic risk factors. J Res Med Sci. 2015;20:294-307.

23. Aguilar A, Ostrow V, De Luca F, Suarez E. Elevated ambulatory blood pressure in a multi-ethnic population of obese children and adolescents. J Pediatr. 2010;156:930-5.

24. Chen W, Srinivasan SR, Elkasabany A, Berenson GS. Cardiovascular risk factors clustering features of insulin resistance syndrome (Syndrome X) in a biracial (Black-White) population of children, adolescents, and young adults: the Bogalusa Heart Study. Am J Epidemiol. 1999;150:667-74.

25. Tounian P, Aggoun Y, Dubern B, Varille V, Guy-Grand B, Sidi D, et al. Presence of increased stiffness of the common carotid artery and endothelial dysfunction in severely obese children: a prospective study. Lancet. 2001;358:1400-4.

26. Arslanian S, Suprasongsin C. Differences in the in vivo insulin secretion and sensitivity of healthy black versus white adolescents. J Pediatr. 1996;129: 440-3.

27. Gregor MF, Hotamisligil GS. Thematic review series: Adipocyte Biology. Adipocyte stress: the endoplasmic reticulum and metabolic disease. J Lipid Res. 2007:48:1905-14.

28. Foucan L, Ezourhi N, Maimaitiming S, Hedreville S, Inamo J, Atallah A, et al. Adiponectin multimers and ADIPOQ T45G in coronary artery disease in Caribbean type 2 diabetic subjects of African descent. Obesity (Silver Spring). 2010;18:1466-8.

29. Arslan N, Erdur B, Aydin A. Hormones and cytokines in childhood obesity. Indian Pediatr. 2010;47:829-39.

30. Villarreal-Molina MT, Antuna-Puente B. Adiponectin: anti-inflammatory and cardioprotective effects. Biochimie. 2012;94:2143-9.

31. Kennedy A, Gettys TW, Watson P, Wallace P, Ganaway E, Pan Q, et al. The metabolic significance of leptin in humans: gender-based differences in relationship to adiposity, insulin sensitivity, and energy expenditure. J Clin Endocrinol Metab. 1997;82:1293-300.

32. Klok MD, Jakobsdottir S, Drent ML. The role of leptin and ghrelin in the regulation of food intake and body weight in humans: A review. Obesity Reviews. 2007;8:21-34.

33. Steinberger J, Steffen L, Jacobs Jr DR, Moran A, Hong CP, Sinaiko AR. Relation of leptin to insulin resistance syndrome in children. Obesity Res. 2003;11:1124-30. 
34. Pelleymounter MA, Cullen MJ, Baker MB, Hecht R, Winters D, Boone T, et al. Effects of the obese gene product on body weight regulation in ob/ob mice. Science. 1995;269:540-3.

35. Dardeno TA, Chou SH, Moon HS, Chamberland JP, Fiorenza CG, Mantzoros CS. Leptin in human physiology and therapeutics. Front Neuroendocrinol. 2010;31:377-93

36. Farooqi IS, Jebb SA, Langmack G, Lawrence E, Cheetham CH, Prentice AM, et al. Effects of recombinant leptin therapy in a child with congenital leptin deficiency. N Engl J Med. 1999;341:879-84.

37. Van Heek M, Compton DS, France CF, Tedesco RP, Fawzi AB, Graziano MP, et al. Diet-induced obese mice develop peripheral, but not central, resistance to leptin. J Clin Invest. 1997;99:385-90.

38. Scarpace PJ, Matheny M, Tumer N. Hypothalamic leptin resistance is associated with impaired leptin signal transduction in aged obese rats. Neuroscience. 2001;104:1111-7.

39. St-Pierre J, Tremblay ML. Modulation of leptin resistance by protein tyrosine phosphatases. Cell Metab. 2012:15:292-7.

40. Goran Ml, Alderete TL. Targeting adipose tissue inflammation to treat the underlying basis of the metabolic complications of obesity. Nestle Nutr Inst Workshop Ser. 2012;73:49-60.

41. Aleffi S, Petrai I, Bertolani C, Parola M, Colombatto S, Novo E, et al. Upregulation of proinflammatory and proangiogenic cytokines by leptin in human hepatic stellate cells. Hepatology. 2005;42:1339-48.

42. Ouchi N, Walsh K. Adiponectin as an anti-inflammatory factor. Clin Chim Acta. 2007;380:24-30.

43. Jeffery AN, Metcalf BS, Hosking J, Streeter AJ, Voss LD, Wilkin TJ. Age before stage: insulin resistance rises before the onset of puberty: a 9-year longitudinal study (EarlyBird 26). Diabetes Care. 2012:35:536-41.

44. Ballabriga A. Morphological and physiological changes during growth: an update. Eur J Clin Nutr. 2000;54 Suppl 1:S1-6.

45. Kamal NN, Ragy MM. The effects of exercise on C-reactive protein, insulin, leptin and some cardiometabolic risk factors in Egyptian children with or without metabolic syndrome. Diabetol Metab Syndr. 2012;4:27.

46. Reinehr T, Roth CL, Alexy U, Kersting M, Kiess W, Andler W. Ghrelin levels before and after reduction of overweight due to a low-fat highcarbohydrate diet in obese children and adolescents. Int J Obes (Lond). 2005:29:362-8

47. Cruz M, García-Macedo R, García-Valerio Y, Gutiérrez M, Medina-Navarro R, Duran $\mathrm{G}$, et al. Low adiponectin levels predict type 2 diabetes in Mexican children. Diabetes Care. 2004;27:1451-3.

48. Ley SH, Harris SB, Connelly PW, Mamakeesick M, Gittelsohn J, Hegele RA, et al. Adipokines and incident type 2 diabetes in an Aboriginal Canadian [corrected] population: the Sandy Lake Health and Diabetes Project. Diabetes Care. 2008:31:1410-5.

49. Spranger J, Kroke A, Möhlig M, Bergmann MM, Ristow M, Boeing H, et al. Adiponectin and protection against type 2 diabetes mellitus. Lancet. 2003;361:226-8.

\section{Submit your next manuscript to BioMed Central and take full advantage of:}

- Convenient online submission

- Thorough peer review

- No space constraints or color figure charges

- Immediate publication on acceptance

- Inclusion in PubMed, CAS, Scopus and Google Scholar

- Research which is freely available for redistribution 